\title{
Effect of the p53 $\alpha$ gene on the chemosensitivity of the H1299 human lung adenocarcinoma cell line
}

\author{
KAISHAN LIU, WEISONG GAO and JUN LIN \\ Department of Pathology, School of Medicine, Jinan University, Guangzhou, Guangdong 510632, P.R. China
}

Received April 1, 2016; Accepted April 6, 2017

DOI: $10.3892 / 01.2017 .6356$

\begin{abstract}
To investigate the effects of tumor protein p53 (p53 or TP53) $\alpha$ gene on the chemosensitivity of the H1299 human lung adenocarcinoma cell line, the recombinant vector pEGFP-p53 $\alpha$ was constructed. The vector pEGFP-p53 $\alpha$ was transfected into the cultured p53-null H1299 cells using Lipofectamine 2000. The G418-resistant cells were then selected. The expression of the p53 $\alpha$ gene in these cells was examined using reverse transcription-polymerase chain reaction, and TP53 protein expression was examined using western blot analysis and immunocytochemistry. An MTT assay and colony formation assay were used to analyze the response of the transfected cells to cisplatin (CDDP). DAPI staining was used to determine the level of apoptosis of the transfected cells. The transfected H1299 human lung adenocarcinoma cells stably expressed TP53 protein. The MTT assay demonstrated that the $50 \%$ inhibitory concentrations for the H1299, H1299/pEGFP-N ${ }_{1}$ and H1299/pEGFP-p53 $\alpha$ cells were 28,24 and $18 \mu \mathrm{mol} / 1$, respectively. The survival rate of H1299/pEGFP-p53 $\alpha$ cells was significantly reduced compared with that of H1299 and H1299/pEGFP-N $\mathrm{N}_{1}$ cells $(\mathrm{P}<0.05)$. The colony formation assay and DAPI staining identified that the colony formation rate and the number of apoptotic cells of H1299/pEGFP-p53 $\alpha$ were significantly reduced, compared with those of the H1299 and H1299/pEGFP-N cells $(\mathrm{P}<0.05)$. Therefor, the present study demonstrated that the transfection of H1299 cells with the p53 $\alpha$ gene resulted in an increase in sensitivity to CDDP chemotherapy. The combination of CDDP and gene therapy for H1299 lung adenocarcinoma cell line provides an experimental basis for clinical research.
\end{abstract}

Correspondence to: Dr Kaishan Liu, Department of Pathology, School of Medicine, Jinan University, 601 West Huangpu Road, Guangzhou, Guangdong 510632, P.R. China

E-mail: tlksh@jnu.edu.cn

Key words: tumor protein p53a gene, lung adenocarcinoma cell, chemosensitivity

\section{Introduction}

Lung cancer is the most frequently diagnosed cancer with a poor prognosis; non-small cell lung cancer (NSCLC) remains the predominant diagnosis among all cases of lung cancer. NSCLC consists of $\sim 85 \%$ of all lung cancer diagnoses, and these primarily consist of the following morphological subtypes: Adenocarcinoma (AC); squamous cell carcinoma (SCC); large cell carcinoma (LCC) $(1,2)$. Although molecular-targeted cancer therapy has advanced considerably, chemotherapy is the primary treatment for lung cancer cases that are unresectable. For patients with advanced NSCLC, the platinum-based two-drug combination regimen is a standard chemotherapy $(3,4)$. Cisplatin (CDDP)-based chemotherapy has improved the survival rate of patients with NSCLC. However, the resistance of tumor cells to this drug still limits its efficacy.

Tumor protein p53 (p53 or TP53), the 'guardian of the genome', was identified in 1979 (5) as the first tumor suppressor gene. p53 is the most extensively studied tumor suppressor gene and has an important role in suppressing tumor development. The function of the p53 gene is to restrict cell proliferation in response to DNA damage. Through the regulation of target genes, p53 is responsible for various cellular responses, including growth arrest, senescence and apoptosis $(6,7)$. The investigation of p53-induced apoptosis in response to genotoxic stress is of clinical importance, as numerous traditional chemotherapeutic strategies rely on the induction of DNA damage and the subsequent activation of apoptosis (8). For example, the mechanism for CDDP is to induce apoptosis via damaging the DNA of cancer cells and activating the p53-dependent apoptosis pathway. However, investigation of p53 biology has established that manipulation of p53 function may provide further insight to the potential of a cancer-free life (9).

p53 regulates the toxic effects of DNA damaging drugs on cancer cells. However, the mutant TP53 proteins lose their 'guardian of the genome' function when mutated, including the functions of arresting cell proliferation and inducing apoptosis (10). Mutations in the p53 gene occur in the majority of malignant tumors. Lung cancer cases have high rates of specific p53 mutations (i.e., mutations to p53 that are present in lung cancer but not other malignant tumors), with $\sim 46 \%$ in lung adenocarcinoma and $\sim 81 \%$ in squamous cell carcinoma of lung (11). At the genetic level, carcinogenesis is a multistep 
process, in which the activation of oncogenes and the inactivation of tumor suppressors participate (12). p53 gene mutations are typically caused by alterations of a single amino acid that results in the expression of mutant proteins with 'gain of function' activity (13). These mutant proteins have been demonstrated to have a dominant oncogenic role $(14,15)$. In certain previous studies, p53 mutations have been reported to be markers of poor survival in $\operatorname{NSCLC~}(16,17)$. As genetic alterations in the p53-dependent apoptosis pathway frequently occur in NSCLC, the understanding of p53 activity in treatment may be valuable for the development of novel therapeutic methods (18).

In the present study, the exogenous wild-type p53 $\alpha$ gene was transfected into p53-null H1299 human lung adenocarcinoma cells, and the cells were screened for those that stably expressed the TP53 protein. The focus of the current study was to investigate whether the expression of wild-type p53a resulted in an increase of the sensitivity of cells to CDDP chemotherapy, and to explore the associated underlying mechanisms.

\section{Materials and methods}

Cell line and cell culture. The human A549 lung adenocarcinoma cell line was purchased from Sun Yat-sen University (Guangdong, China). The human H1299 lung adenocarcinoma cell line was purchased from the Cell Bank of Shanghai (Institute of Cell Biology, Shanghai, China). All cells were cultured in RPMI-1640 (HyClone; GE Healthcare Life Sciences, Logan, UT, USA), supplemented with $10 \%$ fetal bovine serum (Zhejiang Tianhang Biotechnology Co., Ltd., Hangzhou, China), $100 \mathrm{U} / \mathrm{ml}$ penicillin and $100 \mu \mathrm{g} / \mathrm{ml}$ streptomycin (Beyotime Institute of Biotechnology, Shanghai, China) in a humidified atmosphere containing $5 \% \mathrm{CO}_{2}$ in an incubator at $37^{\circ} \mathrm{C}$. All experiments were performed on cells in the logarithmic phase of growth.

Construction and identification of recombinant vector pEGFP-p53 $\alpha$. Total RNA of A549 cells was isolated using TRIzol $^{\circledR}$ (Takara Biotechnology Co., Ltd., Dalian, China), according to the manufacturer's protocol. Total RNA $(1.0 \mu \mathrm{g})$ was reverse-transcribed using AMV Reverse Transcriptase (Takara Biotechnology Co., Ltd.), from which the cDNA was obtained for polymerase chain reaction (PCR) amplification (DNase was not used). The primer sequences were as follows: p53 $\alpha$ forward, 5'-ACT AGA ATT CAT GGA GGA GCC GCA GTC-3' and reverse, 5'-CGC GGG ATC CTC AGT CTG AGT CAG GCC CTT-3'. The PCR amplifications were performed under the following thermocycling conditions: The initial denaturation was at $50^{\circ} \mathrm{C}$ for $30 \mathrm{~min}$ and $94^{\circ} \mathrm{C}$ for $2 \mathrm{~min}$, followed by $25-30$ cycles of denaturation at $94^{\circ} \mathrm{C}$ for $30 \mathrm{sec}$, annealing at $55-65^{\circ} \mathrm{C}$ for $30 \mathrm{sec}$ and extension at $72^{\circ} \mathrm{C}$ for $1 \mathrm{~min}$. The PCR products were separated by electrophoresis on a $1 \%$ agarose gel and were stained by ethidium bromide and visualized using ultraviolet light.

The PCR products were purified from agarose gel using a MiniBest Agarose Gel DNA Extraction kit. (Takara Biotechnology Co., Ltd.). The purified products were ligated into the cloning vector pMD18-T and transformed into JM109 Escherichia coli (all from Takara Biotechnology Co., Ltd.).
The shuttle vector $\mathrm{pEGFP}-\mathrm{N}_{1}$ and anti-sense fragments of the p53 $\alpha$ gene were digested using the restriction enzymes EcoRI and BamHI, respectively (Takara Biotechnology Co., Ltd.). The digested products were purified using the Takara MiniBest Agarose Gel DNA Extraction kit (Takara Biotechnology Co., Ltd.) and ligated with T4 DNA ligase, and then co-transformed into DH-5a E. coli (both from Takara Biotechnology Co., Ltd.). The pEGFP-p53 $\alpha$ was isolated and the successful construction was validated via sequencing analysis.

Gene transfection and G418 selection. $\mathrm{H} 1299$ cells $\left(3 \times 10^{5}\right)$ were seeded in each well of 6-well plates and cultured for $24 \mathrm{~h}$ at $37^{\circ} \mathrm{C}$. The cells were then co-incubated with $10 \mu \mathrm{l}$ Lipofectamine ${ }^{\circledR} 2000$ (Thermo Fisher Scientific, Inc., Waltham, MA, USA) and $4 \mu \mathrm{g}$ plasmid pEGFP-p53 $\alpha$ or pEGFP-N ${ }_{1}$ at $37^{\circ} \mathrm{C}$ for $6 \mathrm{~h}$. Subsequently, the cells were treated with fresh medium followed by an additional $48 \mathrm{~h}$ of incubation at $37^{\circ} \mathrm{C}$. $\mathrm{H} 1299$ cells $\left(5 \times 10^{3}\right)$ were seeded in 24 -well plates. On day 2, G418 (Amresco, LLC, Solon, OH, USA) was added at the following various concentrations: 100, 200, 300, 400, $500,600,700,800,900,1,000$ and $1,100 \mu \mathrm{g} / \mathrm{ml}$. The cells were cultured with $\mathrm{G} 418$ for 2 weeks at $37^{\circ} \mathrm{C}$. The medium was replaced every 3 days. The cells that were resistant to $1,000 \mu \mathrm{g} / \mathrm{ml} \mathrm{G} 418$ were selected using an Olympus BX-51 inverted fluorescent microscope (Olympus Corporation, Tokyo, Japan). The Image Analysis Software GM-SW2000 and Image Measurement Software GM-2000 M were used to visualize the cells (Shanghai Guangmi Instrument Co., Ltd., Shanghai, China). The transfection efficiency was quantified by assessing GFP fluorescence intensity at a wavelength of $590 \mathrm{~nm}$.

Reverse transcription (RT)-PCR analysis. Total RNA was extracted from the control group and the stable-transfection H1299 cells. Total RNA was reverse-transcribed using AMV reverse transcriptase, from which the cDNA was used for PCR amplification with Takara Ex Taq polymerase. The PCR reaction was performed using the following primers: p53 $\alpha$ forward, 5'-ACT AGA ATT CAT GGA GGA GCC GCA GTC-3' and reverse, 5'-CGC GGG ATC CTC AGT CTG AGT CAG GCC CTT-3. RT-PCR was performed for 1 cycle at $50^{\circ} \mathrm{C}$ for $30 \mathrm{~min}$ and $94^{\circ} \mathrm{C}$ for $2 \mathrm{~min}$ followed by 28 cycles of $94^{\circ} \mathrm{C}$ for $30 \mathrm{sec}, 55^{\circ} \mathrm{C}$ for $30 \mathrm{sec}$ and $72^{\circ} \mathrm{C}$ for $1 \mathrm{~min}$. In total, $5 \mu \mathrm{l}$ PCR products stained with ethidium bromide were separated by electrophoresis on a $1 \%$ agarose gel and were visualized under ultraviolet light. All reagents were supplied by Takara Biotechnology Co., Ltd.

Western blot analysis. Total protein was extracted from the control group and stable-transfection H1299 cells on ice. Equal amounts of protein from the samples $(60 \mu \mathrm{g})$ were quantified using a Bicinchoninic Protein Assay kit (Beyotime Institute of Biotechnology, Haimen, China), and then separated on a $12 \%$ SDS-PAGE gel prior to being transferred to polyvinylidene fluoride membranes (Merck KGaA, Darmstadt, Germany). The immune complexes were formed through the incubation of the proteins with 1:1,000 rabbit monoclonal anti-p53 (cat. no. 9282; Cell Signaling Technology, Inc., Danvers, MA, USA) and 1:1,000 rabbit anti- $\beta$-actin (cat. no. 4967; Bioworld Technology, Inc., St. Louis Park, MN, USA) primary antibodies at $4^{\circ} \mathrm{C}$ overnight. The membranes were blocked in $5 \%$ 
skimmed milk for at room temperature $1 \mathrm{~h}$ and incubated with horseradish peroxidase (HRP)-conjugated anti-rabbit IgG antibodies (cat. no. 7074; Cell Signaling Technology, Inc.) at a dilution of 1:3,000 at room temperature for $1 \mathrm{~h}$. Next, the membrane was washed three times with Tris-buffered saline-Tween-20 and the protein bands were visualized using an enhanced chemiluminescence kit (cat. no. 12630; Cell Signaling Technology, Inc.) and the signals on the membranes were exposed to X-ray films.

Immunocytochemistry. Transfected and non-transfected H1299 cells were seeded at density of $1.5 \times 10^{5}$ cells/well in 6-well plates and cultured overnight at $37^{\circ} \mathrm{C}$. The cells on slide inside 6-well plates were washed with PBS, fixed with $4 \%$ paraformaldehyde for $30 \mathrm{~min}$ at room temperature and permeabilized with $0.1 \%$ Triton $\mathrm{X}-100$ for $15 \mathrm{~min}$ at room temperature. The immune complexes were formed by incubating the proteins with a 1:160 rabbit anti-p53 monoclonal antibody at $4{ }^{\circ} \mathrm{C}$ overnight. A horseradish peroxidase (HRP)-conjugated anti-rabbit IgG antibody (cat. no. 7074; Cell Signaling Technology, Inc.) was then added and the slides were incubated at room temperature for $30 \mathrm{~min}$ and then washed with PBS three times. Development of the slides was performed using 3,3'-diaminobenzidine solution for 8-10 min at room temperature. The slides were washed in PBS for $5 \mathrm{~min}$, counterstained with hematoxylin for $2 \mathrm{~min}$ and dehydrated with ethanol for $5 \mathrm{~min}$ at room temperature prior to the addition of the transparent neutral balsam mounting medium and coverslips. Unless stated, all reagents were supplied by Fuzhou Maixin Biotech Co., Ltd., Fuzhou, China.

MTT assay and estimation of half-maximal inhibitory concentration $\left(I C_{50}\right)$ values. Transfected and non-transfected H1299 cells were seeded at a density of $3.5 \times 10^{3}$ cells/well in 96-well plates and incubated overnight at $37^{\circ} \mathrm{C}$. CDDP was added at numerous concentrations: $0.01,0.05,0.25,1.25,10$, 20 and $30 \mu \mathrm{mol} / 1$. CDDP was administered for $48 \mathrm{~h}$ at $37^{\circ} \mathrm{C}$. The MTT (Sigma-Aldrich; Merck KGaA) reagent (20 $\mu \mathrm{l}$ of $5 \mathrm{mg} / \mathrm{ml}$ ) was added and incubated for $4 \mathrm{~h}$ at $37^{\circ} \mathrm{C}$. The reaction was stopped by the addition of $150 \mu \mathrm{l}$ dimethyl sulfoxide. The optical density at a wavelength of $570 \mathrm{~nm}$ was determined on a microplate reader and the untreated cells were used as the control for $100 \%$ viability. The $\mathrm{IC}_{50}$ values were calculated from the dose-response data and was the concentration required to inhibit cell growth by $50 \%$ compared with the untreated control. Values were estimated using dose-concentration curves showing the percent of cell count.

Clone formation assay. Transfected and non-transfected H1299 cells were seeded in triplicate in 6-well plates at density of 200 cells/well. After $24 \mathrm{~h}$, cells in the growth phase were treated with $0.25 \mu \mathrm{mol} / 1 \mathrm{CDDP}$ for $48 \mathrm{~h}$ at $37^{\circ} \mathrm{C}$. They were then cultured for 14 days in an atmosphere containing $5 \% \mathrm{CO}_{2}$ at $37^{\circ} \mathrm{C}$ to facilitate colony formation. Following washing with PBS twice, the colonies were fixed with $4 \%$ paraformaldehyde for $30 \mathrm{~min}$ at room temperature. Subsequently, the fixed solution was discarded, $1 \mathrm{ml}$ diluted Giemsa dye (1:9 dilution in PBS; Huamei Biotechnology Co., Ltd., Wuhan, China) was added and the colonies were stained for $30 \mathrm{~min}$ at room temperature. Finally, the positive colonies ( $>50$ cells/colony) were counted.

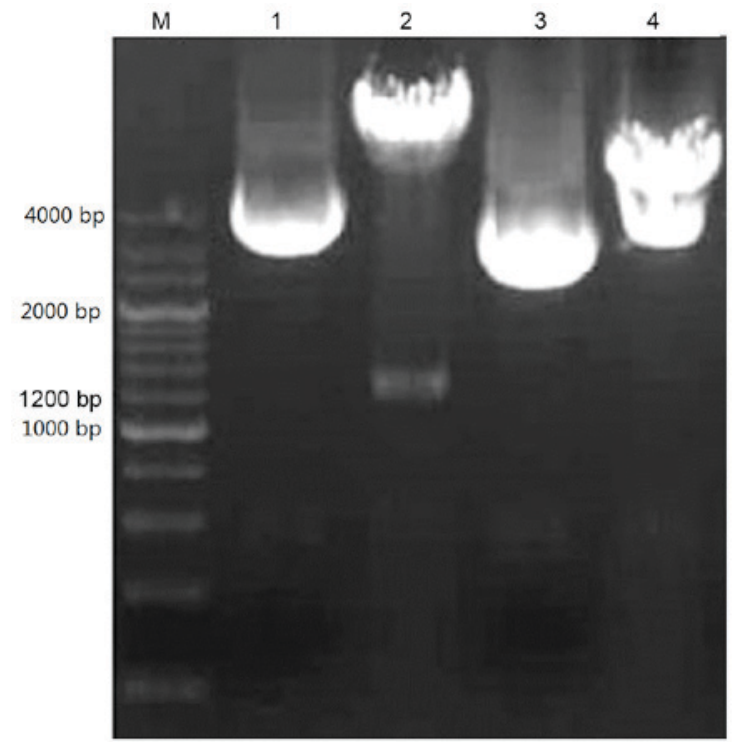

Figure 1. Restriction enzyme digest of pEGFP-p53 $\alpha$ with EcoRI and BamHI. M, marker. Lane 1, 3 and 4, pEGFP-N ${ }_{1}$; Lane 2, pEGFP-p53 $\alpha$. p53, tumor protein p53; bp, base pairs.

The survival fraction was calculated using the following formula: Survival fraction=number of colonies $/ 200$ cells.

DAPI staining of apoptotic nuclei. DAPI stain (Roche Applied Science, Rotkreuz, Switzerland) was used to evaluate drug-associated apoptosis, according to the manufacturer's protocol. Transfected and non-transfected H1299 cells (80\% confluent) were seeded onto the slides in 6-well plates overnight and exposed to $20 \mu \mathrm{mol} / 1 \mathrm{CDDP}$ for $48 \mathrm{~h}$ at $37^{\circ} \mathrm{C}$. Next, the cells were fixed with $4 \%$ paraformaldehyde at room temperature for $30 \mathrm{~min}$ and stained with $0.5 \%$ DAPI for 15-20 min. The stained cells were visualized at X100 magnification and images were captured using an inverted fluorescence microscope (Olympus BX-51; Olympus Corporation).

Statistical analysis. All data analysis was performed using SPSS v13.0 (SPSS, Inc., Chicago, IL, USA). Data are presented as the mean \pm standard deviation. Differences between two groups were determined using Student's or Welch's t-test. $\mathrm{P}<0.05$ was considered to indicate a statistically significant difference.

\section{Results}

Construction and identification of recombinant vector pEGFP-p53 $\alpha$. The PCR product of the plasmid was $\sim 1,200$ base pairs (bp), and was separated using $1 \%$ agarose gel electrophoresis. As presented in Fig. 1, the p53 $\alpha$ gene was isolated from the recombinant shuttle vector $\mathrm{pEGFP}-\mathrm{N}_{1}$ using restriction digestion with EcoRI and BamHI. The $4.7 \mathrm{~kb}$ and $1.2 \mathrm{~kb}$ strips were detected using $1 \%$ agarose gel electrophoresis, representing the shuttle vector $\mathrm{pEGFP}-\mathrm{N}_{1}$ and the fragment of the p53 $\alpha$ gene, respectively. The expression of the $\mathrm{p} 53 \alpha$ gene was verified using gene sequence examination (data not presented). The recombinant vector pEGFP-p53 $\alpha$ was established successfully.

G418 selection and gene transfection. The H1299 cells were seeded in 24-well plates with various concentrations of G418 
A

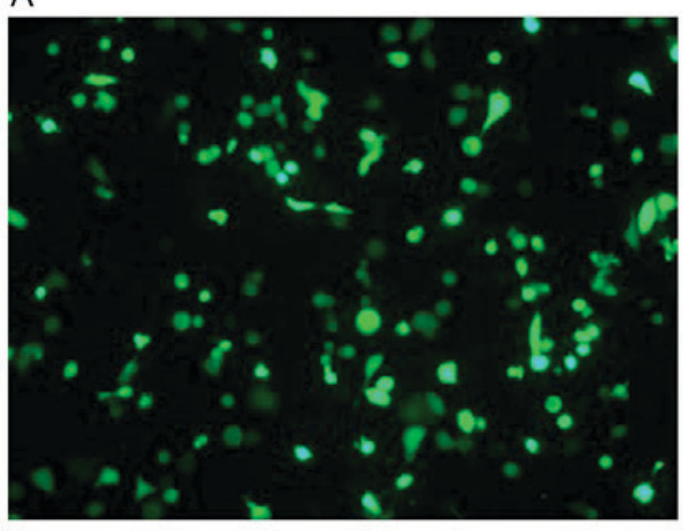

C

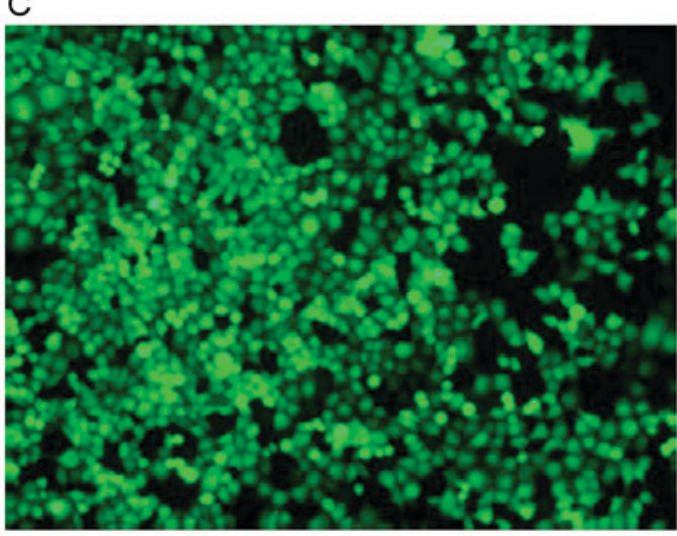

B

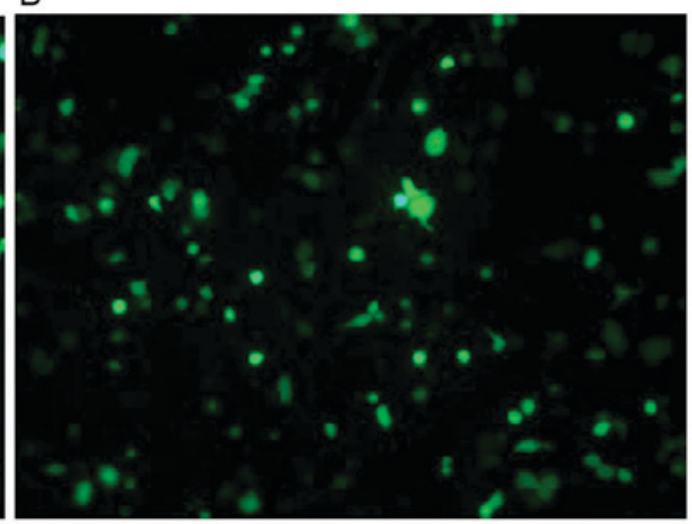

$\mathrm{D}$

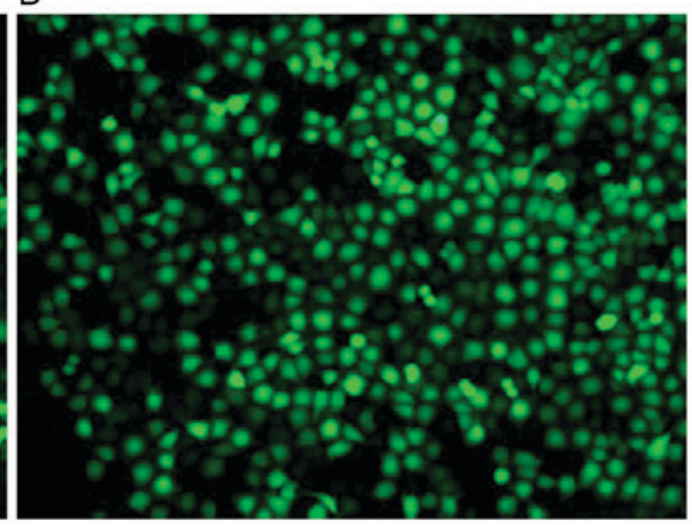

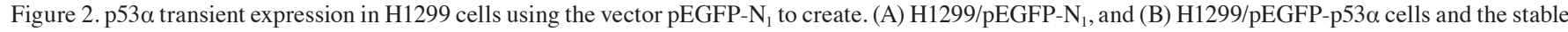
cell lines (C) H1299/pEGFP-N 1 and (D) H1299/pEGFP-p53 $\alpha$ cells. Magnification, x100. p53, tumor protein p53.

and the pEGF-p53 $\alpha$ screening concentration of G418 was $1,000 \mu \mathrm{g} / \mathrm{ml}$. Recombinant pEGFP-p53 $\alpha$ was transfected into H1299 cells with Lipofectamine 2000 for 2 days. The green fluorescence was monitored using fluorescence microscopy. The cells that were resistant to G418 were selected. As presented in Fig. 2, the efficiency of the pEGFP-N $\mathrm{N}_{1}$ vector transfection was high, compared with that of the pEGFP-p53 $\alpha$ recombinant vector transfection.

Identification of the stable expression cell line $H 1299 / p E G F P-p 53 \alpha$. The expression of the p53 $\alpha$ gene in the cells was evaluated using RT-PCR. TP53 protein was evaluated using western blot analysis and immunocytochemistry. As depicted in Fig. 3, the fragment of 1,200 bp was obtained using RT-PCR amplification. The TP53 protein band was observed in H1299/pEGFP-p53 $\alpha$ cells using western blot analysis (Fig. 4). The expression of TP53 was also investigated using immunocytochemistry in the control group and stable-transfection H1299 cells. The H1299 and H1299/pEGFP-N transfected $_{1}$ groups demonstrated no positive TP53 staining. However the H1299/pEGFP-p53 $\alpha$ transfected group exhibited the brown color of the TP53 stain (Fig. 5). Therefore, exogenous TP53 was successfully expressed in H1299/pEGFP-p53 $\alpha$ cells.

\section{Effects of p53a gene on chemosensitivity}

MTT assay results. $\mathrm{IC}_{50}$ values in comparison with the untreated control were estimated for the H1299 and H1299/pEGFP-N control groups and the H1299/pEGFP-p53 $\alpha$ test group cells by deriving dose-response curves from the percentage of cells that survived treatment, as obtained from the cell counts (Fig. 6). The values for H1299, H1299/pEGFP-N ${ }_{1}$ and H1299/pEGFP-p53 $\alpha$ cells were 28, 24 and $18 \mu \mathrm{mol} / 1$, respectively. Although the $\mathrm{IC}_{50}$ values did not differ significantly between the H1299 and H1299/pEGFP-N ${ }_{1}$ cells $(\mathrm{P}>0.05)$, the value for the H1299/pEGFP-p53 $\alpha$ cells was significantly reduced compared with those of $\mathrm{H} 1299$ and H1299/pEGFP-N cells $(\mathrm{P}<0.05)$.

Clone formation assay results. The survival fractions [calculated as follows: Survival fraction $(\%)=$ number of colonies/200 cells] of control groups prior to CDDP treatment were as follows: H1299, 43.6 $\pm 0.23 \%$; H1299/pEGFP-N ${ }_{1}$, $41.8 \pm 0.13 \%$. There was no significant difference between these two groups. Following treatment with $0.25 \mu \mathrm{mol} / 1 \mathrm{CDDP}$, the survival fractions in the H1299 and H1299/pEGFP-N ${ }_{1}$ groups were $18.4 \pm 0.10$ and $17.8 \pm 0.01 \%$, respectively, and were not significantly different $(\mathrm{P}>0.05)$. However, the survival fraction in the H1299/pEGFP-p53 $\alpha$ group following CDDP treatment was $13.8 \pm 0.01 \%$. When compared with the control group H1299 $(18.4 \pm 0.10 \%)$, there was a significant difference in colony-formation rate $(\mathrm{P}<0.05$; Figs. 7 and 8$)$.

Cell apoptosis results. The apoptotic cells indicated by DAPI staining are illustrated in Fig. 9. Following treatment with CDDP for $48 \mathrm{~h}$, the cells in the control group and the H1299/pEGFP-p53 $\alpha$ group appeared to reduce in size, and the shapes of the cellular nuclei were irregular. There was no significant difference in the mean number of apoptotic cells between 

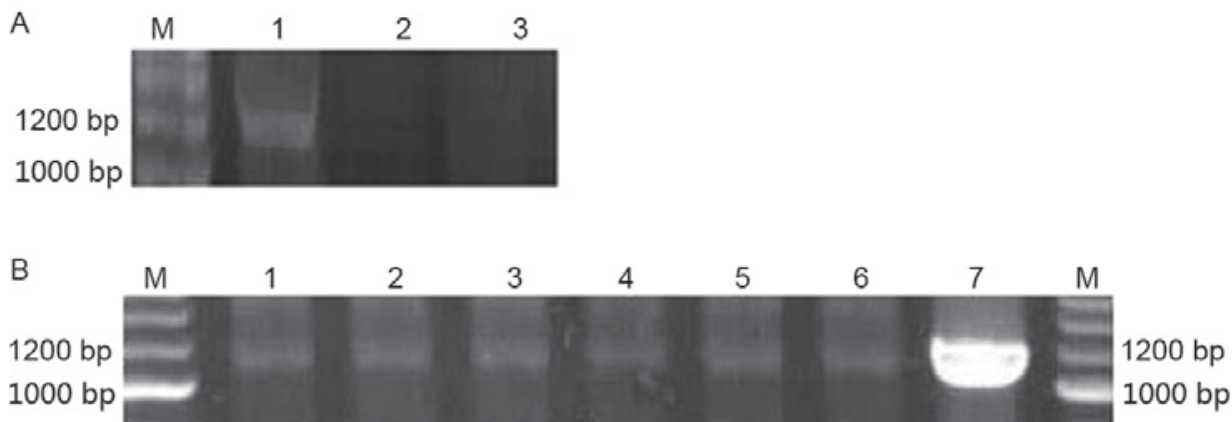

Figure 3. p53 $\alpha$ RNA expression levels evaluated using RT-PCR. (A) p53 $\alpha$ transient expression in H1299 cells at the RNA level as determined by RT-PCR. M,

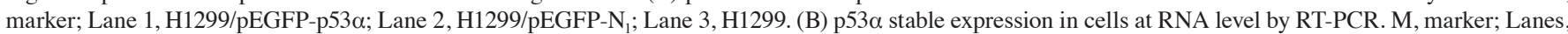
1-6, H1299/pEGFP-p53a; Lane 7, A549. bp, base pairs; RT-PCR, reverse transcription-polymerase chain reaction; p53, tumor protein p53.
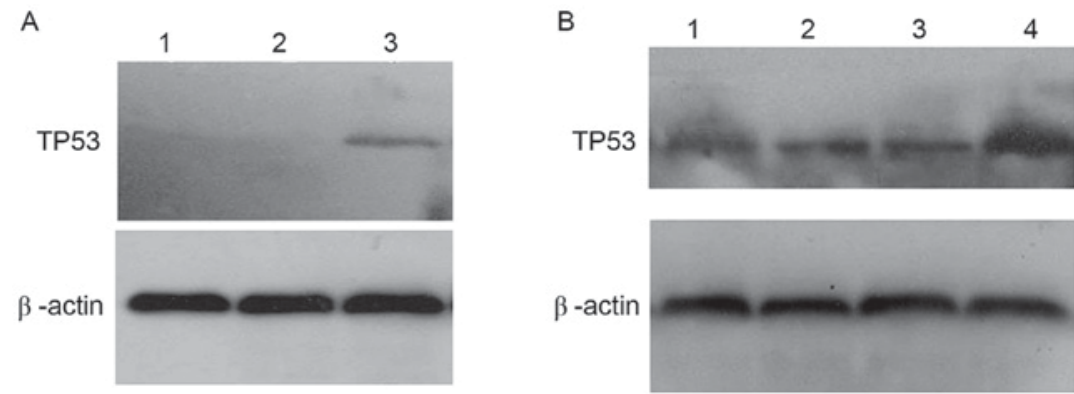

Figure 4. TP53 protein expression evaluated using western blot analysis. (A) TP53 transient protein expression in H1299 cells. Lane 1, H1299; Lane 2,

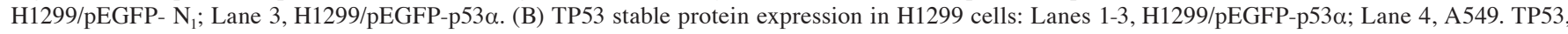
tumor protein $\mathrm{p} 53$.

A

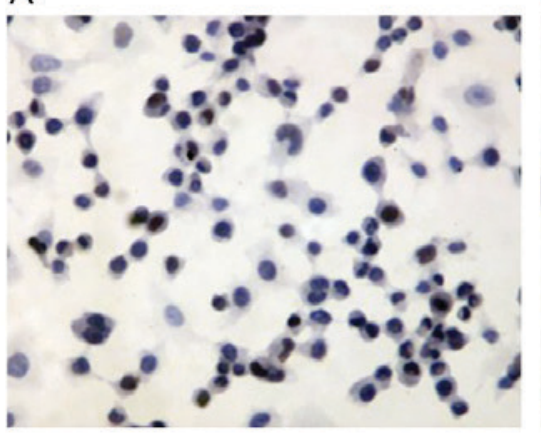

$B$

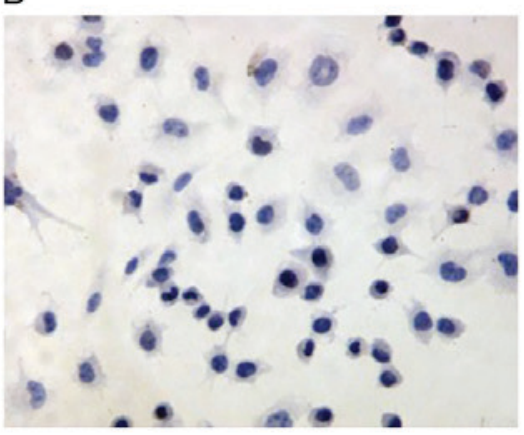

C

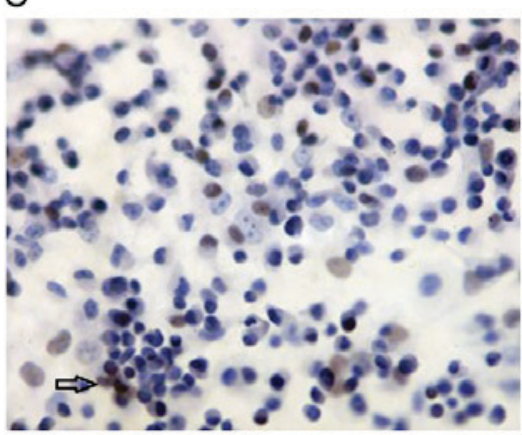

Figure 5. TP53 protein expression evaluated using immunocy tochemistry. TP53 stain in (A) H1299 cells, (B) H1299/pEGFP-N cells and (C) H1299/pEGFP-p53 $\alpha$ cells. Brown staining was identified to be positive TP53 staining. Arrow indicates an example of a positive cell. Magnification, x200. TP53, tumor protein p53.

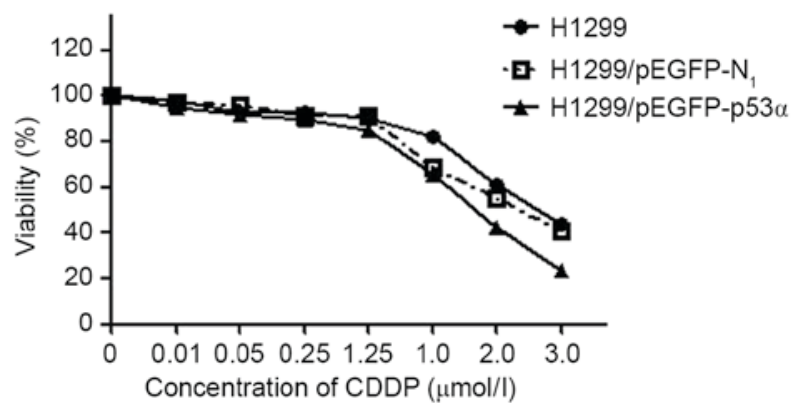

Figure 6. Growth inhibition dose-response curves for H1299, H1299/pEGFP-N ${ }_{1}$ and H1299/pEGFP-p53 $\alpha$ cells in response to CDDP. p53, tumor protein $\mathrm{p} 53$; CDDP, cisplatin.

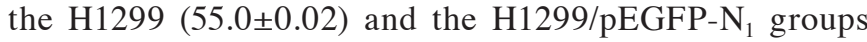
(48.5 \pm 0.08$)$. The highest mean number of apoptotic cells was observed following CDDP therapy in the H1299/pEGFP-p53 $\alpha$ group (89.4 \pm 0.08$)$, in which $\mathrm{P}<0.05$ compared with the $\mathrm{H} 1299$ control group (Fig. 10).

\section{Discussion}

p53 is associated with lung carcinogenesis and treatment. In total $40 \%$ of patients with NSCLC are candidates for systemic chemotherapy, despite the majority of patients with NSCLC being typically resistant to chemotherapy at the time of diagnosis (19). Although chemical agents, including CDDP, doxorubicin and 
A
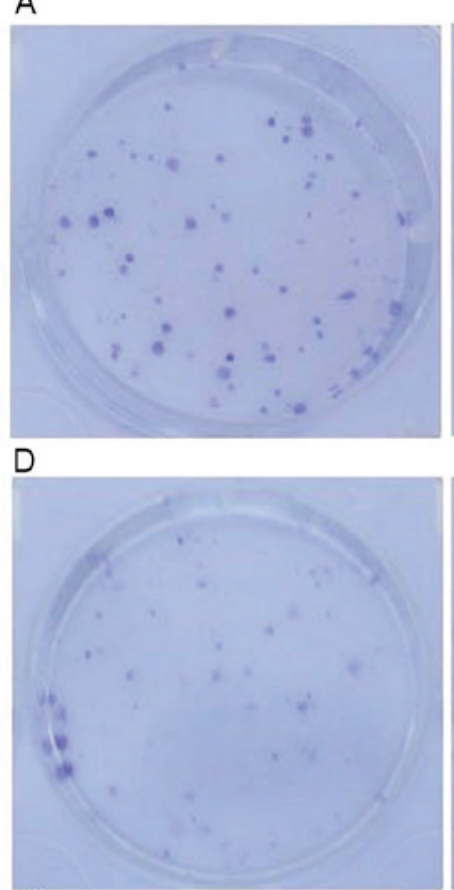

B

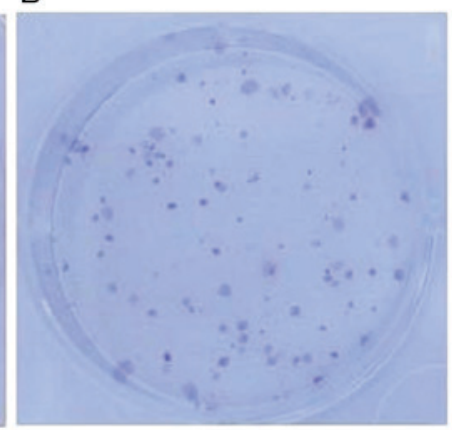

E

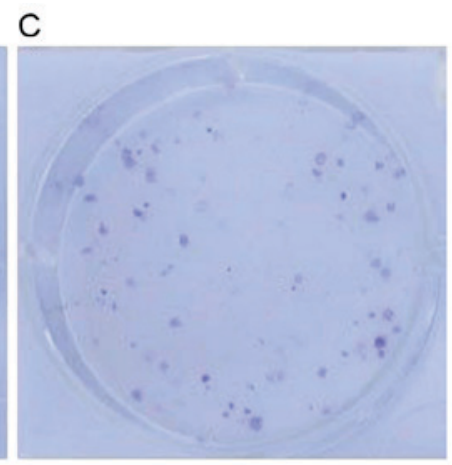

$\mathrm{F}$
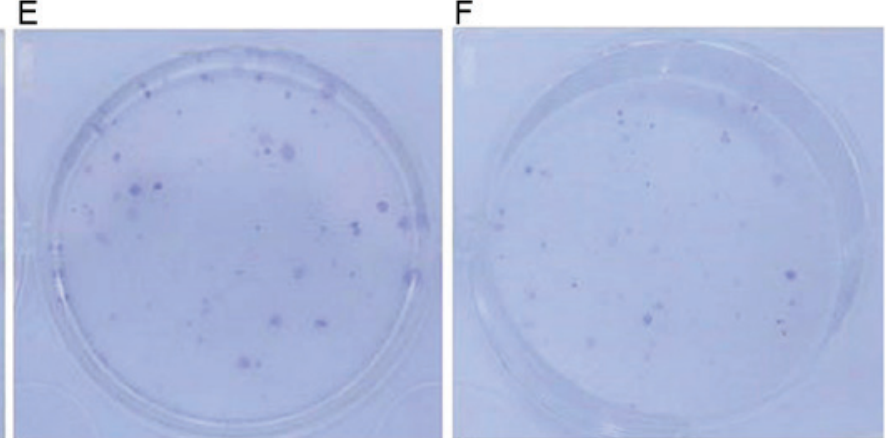

Figure 7. H1299 cells were exposed to $0.25 \mu \mathrm{mol} / 1 \mathrm{CDDP}$ chemotherapy drug for $48 \mathrm{~h}$ and colony formation was measured using clonogenic cell survival after 14 days. (A) Untreated H1299 cells. (B) Untreated H1299/pEGFP-N ${ }_{1}$ cells. (C) Untreated H1299/pEGFP-p53a cells. (D) H1299 cells exposed to CDDP. (E) H1299/pEGFP-N $\mathrm{N}_{1}$ cells exposed to CDDP. (F) H1299/pEGFP-p53 $\alpha$ cells exposed to CDDP. p53, tumor protein p53; CDDP, cisplatin.

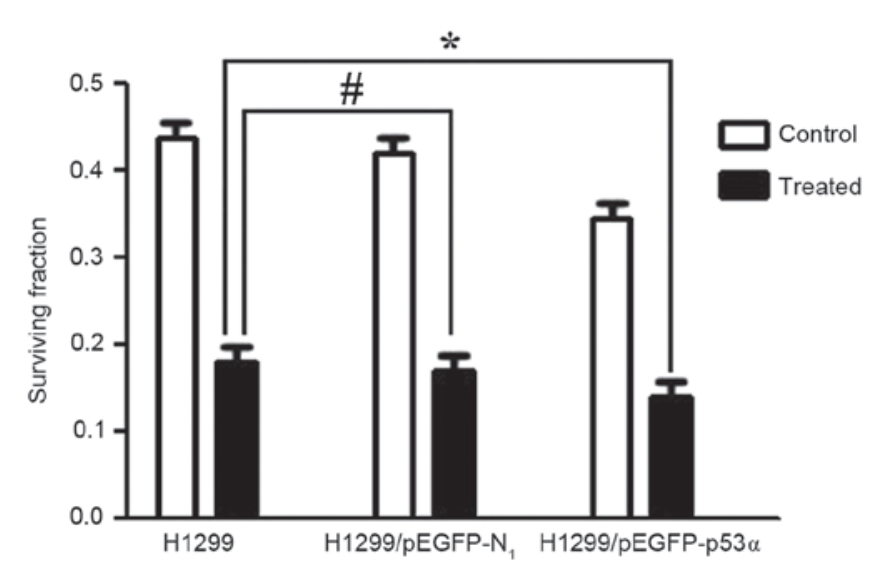

Figure 8 . H1299 cells were exposed to $0.25 \mu \mathrm{mol} / 1$ cisplatin for $48 \mathrm{~h}$. The extent of colony formation was quantified using clonogenic cell survival analysis. Error bars indicate the standard deviation from the mean. ${ }^{*} \mathrm{P}=0.565$, ${ }^{*} \mathrm{P}=0.02 ; \mathrm{P}<0.05$ using the Welch's t-test. p53, tumor protein $\mathrm{p} 53$.

gemcitabine, damage the DNA of tumor cells and consequently activate p53, which leads to cell death, a variety of p53 gene mutations may present an obstacle to conventional chemotherapy. p53 gene mutations are typically caused by alterations of a single amino acid, which results in the expression of mutant proteins with gain-of-function activity. p53 protein loses its 'guardian of the genome' function when mutated, preventing it from arresting cell proliferation or inducing apoptosis $(10,13)$. Therefore, maintaining the normal function of p53 gene is essential for effective lung cancer treatment.

In the present study, the full-length p53 gene was successfully transfected into the H1299 cell line (p53 $3^{-/-}$;
Figs. 1 and 2). The expression of transfected p53 $\alpha$ by H1299 cells was corroborated at the mRNA and protein levels (Figs. 3-5). These results demonstrated that p53 $\alpha$ gene transfection inhibits the growth of $\mathrm{H} 1299$ cells. The $\mathrm{IC}_{50}$ of CDDP decreased following p53 $\alpha$ gene transfection suggesting that p53 and the concentration of CDDP had synergistic effects on inhibiting cell growth (Fig. 6). The p53 $\alpha$ gene transfection also inhibited the colony formation of H1299 cells (Fig. 7 and 8). The results of the current study suggest that $\mathrm{p} 53 \alpha$ cooperates with DNA-damaging drugs in inducing apoptosis in H1299 cells (Figs. 9 and 10). Therefore, p53 gene transfection may allow a reduction in the dose of chemotherapeutic agents and minimize harmful side effects.

Various current strategies have been employed to identify compounds that activate wild-type p53 or restore wild-type function to mutated p53 (20). However, there are certain obstacles for clinical translation (21). For example, adenovirus-mediated p53 (Ad-p53) is now commercially available as Gendicine from Shenzhen SiBiono GeneTech Company, Ltd. (Shenzhen, China) and is currently approved for clinical use in China $(6,22)$. However, Ad-p53 has not been approved for use in Europe and the US due to its toxicity (23). In order to reduce the toxicity of adenovirus-mediated transfection and maintain the effects of p53, the current study investigated liposome-mediated p53 $\alpha$ gene transfection. Non-viral mediated gene therapy has the advantages of safety and convenience. Combined therapy of agents with differing mechanisms of action is feasible and effective in minimizing side effects and avoiding resistance to chemotherapeutic drugs, whilst still promoting the antitumor benefits, which may lead to novel treatment regimes for NSCLC (24). 
A

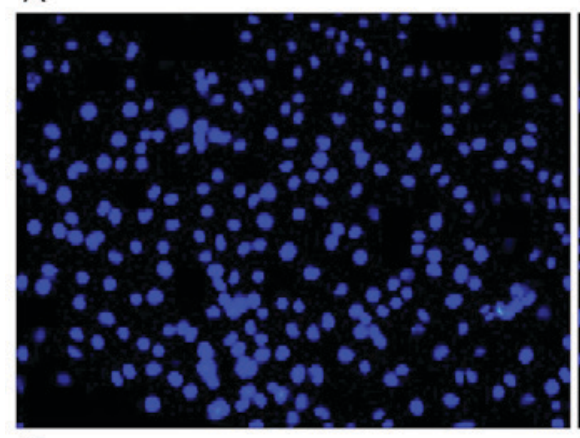

D

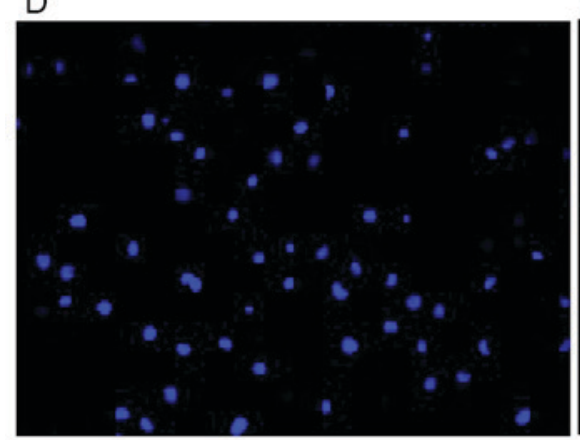

B

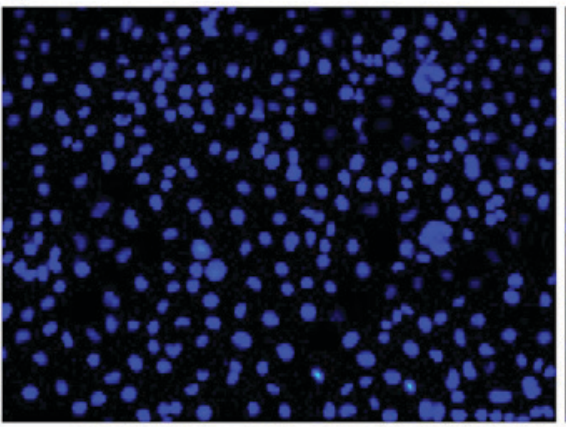

$\mathrm{E}$

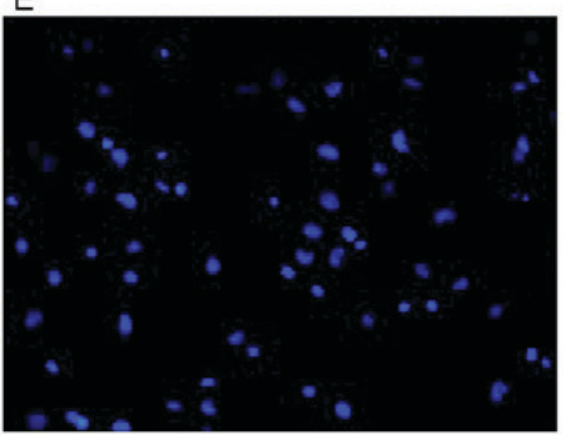

C

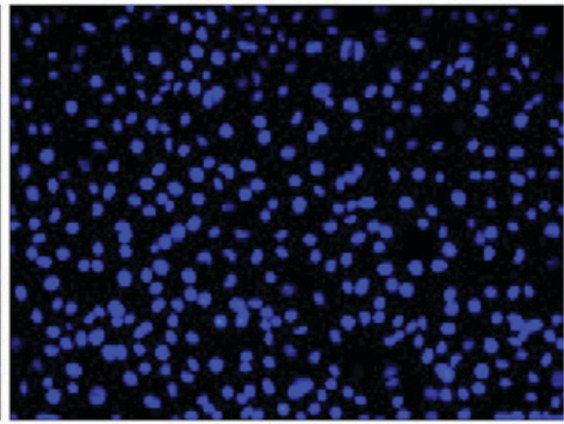

$\mathrm{F}$

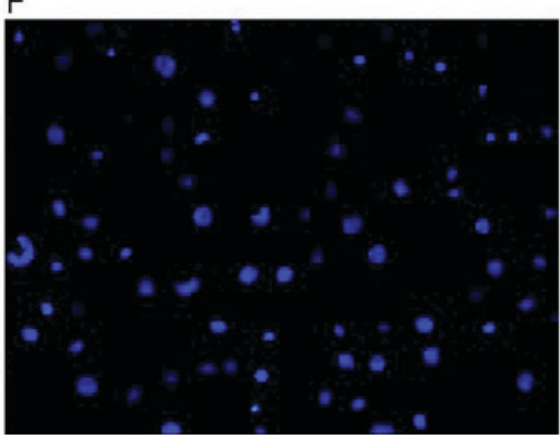

Figure 9. Apoptotic cells revealed by DAPI staining were detected by fluorescence microscopy, at an absorbance wavelength of 500 nm. (A) Untreated H1299 cells. (B) Untreated H1299/pEGFP-N ${ }_{1}$ cells. (C) Untreated H1299/pEGFP-p53 $\alpha$ cells. (D) H1299 cells exposed to CDDP. (E) H1299/pEGFP-N 1 cells exposed to $20 \mu \mathrm{mol} / 1$ CDDP. (F) H1299/pEGFP-p53 $\alpha$ cells exposed to $20 \mu \mathrm{mol} / 1$ CDDP. Magnification, x100. CDDP, cisplatin; p53, tumor protein p53.

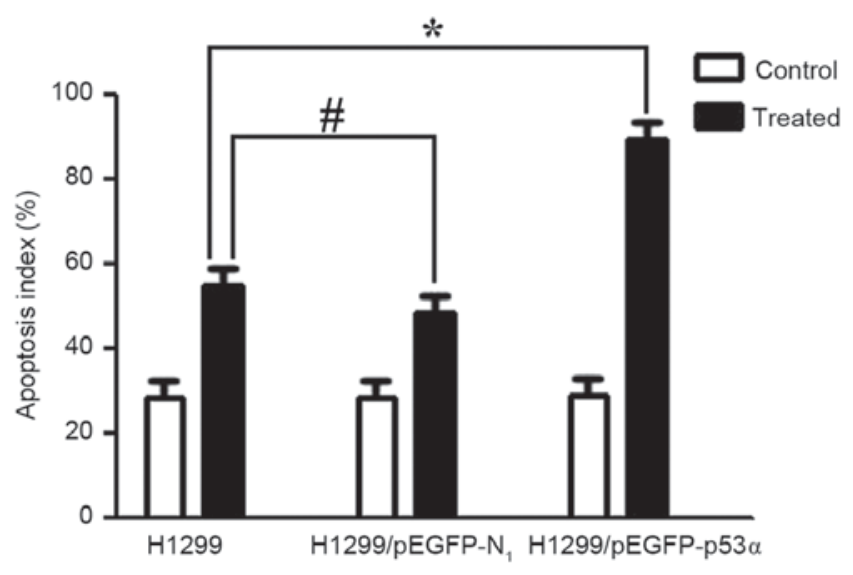

Figure 10. Cells were exposed to $20 \mu \mathrm{mol} / 1$ cisplatin. The mean number of apoptotic cells is indicated in the bar graph. Error bars indicate the standard deviation from the mean. ${ }^{\#} \mathrm{P}=0.651,{ }^{*} \mathrm{P}=0.034 ; \mathrm{P}<0.05$ using Welch's t-test. p53, tumor protein p53.

In conclusion, the transfection of $\mathrm{H} 1299$ cells with the p53 $\alpha$ gene resulted in an increase in sensitivity to CDDP chemotherapy. The present study used the combination of p53 gene therapy and chemotherapy in lung cancer cells and has provided an experimental basis for future clinical trials. Further chemotherapeutic drugs and experiments in vivo are required to confirm the results of the present study.

\section{Acknowledgements}

Data published in this article are part of the medical thesis of Ms. Weisong Gao.

\section{References}

1. Shao C, Lu C, Chen L, Koty PP, Cobos E and Gao W: p53-dependent anticancer effects of leptomycin $\mathrm{B}$ on lung adenocarcinoma. Cancer Chemother Pharmacol 67: 1369-1380, 2011.

2. Monroy-Estrada HI, Chirino YI, Soria-Mercado IE and Sánchez-Rodríguez J: Toxins from the Caribbean sea anemone Bunodeopsis globulifera increase cisplatin-induced cytotoxicity of lung adenocarcinoma cells. J Venom Anim Toxins Incl Trop Dis 19: 12, 2013.

3. Ning X, Sun Z, Wang Y, Zhou J, Chen S, Chen D and Zhang H: Docetaxel plus trans-tracheal injection of adenoviral-mediated p53 versus docetaxel alone in patients with previously treated non-small-cell lung cancer. Cancer Gene Ther 18: 444-449, 2011.

4. Al-Taweel N, Varghese E, Florea A and Büsselberg D: Cisplatin (CDDP) triggers cell death of MCF-7 cells following disruption of intracellular calcium ([Ca (2+)]i) homeostasis. J Toxicol Sci 39: 765-774, 2014.

5. Saha MN, Qiu L and Chang H: Targeting p53 by small molecules in hematological malignancies. J Hematol Oncol 6: 23, 2013.

6. Guan YS, Liu Y, Zou Q, He Q, La Z, Yang L and Hu Y: Adenovirus-mediated wild-type p53 gene transfer in combination with bronchial arterial infusion for treatment of advanced non-small-cell lung cancer, one year follow-up. J Zhejiang Univ Sci B 10: 331-340, 2009.

7. Ma JT, Han CB, Zhao JZ, Jing W, Zhou Y, Huang LT and Zou HW: Synergistic cytotoxic effects of recombinant human adenovirus p53 and radiation at various time points in A549 lung adenocarcinoma cells. Oncol Lett 4: 529-533, 2012.

8. Pietsch EC, Sykes SM, McMahon SB and Murphy ME: The p53 family and programmed cell death. Oncogene 27: 6507-6521, 2008.

9. Selivanova G: Therapeutic targeting of $\mathrm{p} 53$ by small molecules. Semin Cancer Biol 20: 46-56, 2010.

10. Rousseau B, Jacquot C, Le Palabe J, Malleter M, Tomasoni C, Boutard T, Sakanyan V and Roussakis C: TP53 transcription factor for the NEDD9/HEF1/Cas-L gene: Potential targets in non-small cell lung cancer treatment. Sci Rep 5: 10356, 2015.

11. Muller PA and Vousden KH: p53 mutations in cancer. Nat Cell Biol 15: 2-8, 2013.

12. Liu X, Lin XJ, Wang CP, Yan KK, Zhao LY, An WX and Liu XD: Association between smoking and p53 mutation in lung cancer: A meta-analysis. Clin Oncol (R Coll Radiol) 26: 18-24, 2014. 
13. Zhao J, Lu Y and Shen HM: Targeting p53 as a therapeutic strategy in sensitizing TRAIL-induced apoptosis in cancer cells. Cancer Lett 314: 8-23, 2012.

14. Vaughan CA, Frum R, Pearsall I, Singh S, Windle B, Yeudall A, Deb SP and Deb S: Allele specific gain-of-function activity of P53 mutants in lung cancer cells. Biochem Biophys Res Commun 428: 6-10, 2012.

15. Gibbons DL, Byers LA and Kurie JM: Smoking, p53 mutation, and lung cancer. Mol Cancer Res 12: 3-13, 2014.

16. Mattioni M,Soddu S,Prodosmo A, Visca P,Conti S, AlessandriniG, Facciolo F and Strigari L: Prognostic role of serum p53 antibodies in lung cancer. BMC cancer 15: 148, 2015.

17. Machado-Silva A,Perrier S and Bourdon JC: p53 family members in cancer diagnosis and treatment. Semin Cancer Biol 20: 57-62, 2010.

18. Mogi A and Kuwano H: TP53 mutations in nonsmall cell lung cancer. J Biomed Biotechnol 2011: 583929, 2011.

19. Muller PA and Vousden KH: Mutant p53 in cancer: New functions and therapeutic opportunities. Cancer Cell 25: 304-317, 2014.
20. Vassilev LT, Vu BT, Graves B, Carvajal D, Podlaski F, Filipovic Z, Kong N, Kammlott U, Lukacs C, Klein C, et al: In vivo activation of the p53 pathway by small-molecule antagonists of MDM2. Science 303: 844-848, 2004.

21. Yu X, Narayanan S, Vazquez A and Carpizo DR: Small molecule compounds targeting the p53 pathway: Are we finally making progress? Apoptosis 19: 1055-1068, 2014.

22. Yu M, Chen $\mathrm{W}$ and Zhang J: p53 gene therapy for pulmonary metastasis tumor from hepatocellular carcinoma. Anticancer Drugs 21: 882-884, 2010.

23. Duffy MJ, Synnott NC, McGowan PM, Crown J, O'Connor D and Gallagher WM: p53 as a target for the treatment of cancer. Cancer Treat Rev 40: 1153-1160, 2014.

24. Zhang Y, Zhang Q, Zeng SX, Hao Q and Lu H: Inauhzin sensitizes p53-dependent cytotoxicity and tumor suppression of chemotherapeutic agents. Neoplasia 15: 523-534, 2013. 